\title{
Free space-planning solutions in the architecture of multi-storey buildings
}

\author{
Alexander Ibragimov ${ }^{1, *}$ and Alexander Danilov ${ }^{1}$ \\ ${ }^{1}$ Moscow State University of Civil Engineering, Yaroslavskoye shosse 26, Moscow, 129337, Russia
}

\begin{abstract}
Here some aspects of the development of steel frame structure design from the standpoint of geometry and morphogenesis of bearing steel structures of civil engineering objects. An alternative approach to forming constructive schemes may be application of curved steel elements in the main load-bearing system. As an example, it may be circular and parabolic arches or segments of varying outline and orientation. The considered approach implies creating large internal volumes without loss in the loadbearing capacity of the frame. The basic concept makes possible a wide variety of layout and design solutions. The presence of free internal spaces of large volume in buildings of a "skyscraper" type contributes to resolving a great number of problems, including those of communicative nature.
\end{abstract}

\section{Introduction}

A revolutionary qualitative uplift in the construction industry in general and, in particular, in multi-storey construction occurred in connection with the expansion of reinforced concrete and steel structures. The history of construction of high-rise buildings has many centuries and even thousands of years and as such is in itself an interesting subject of research. Buildings with load-bearing walls up to ten stories tall were built in the cities of the Roman Empire. Since the subject of analysis in this paper are essentially multistorey buildings with a steel frame, here it is necessary to confine ourselves to the nearest two past centuries. Various aspects of the development of the construction of high-rise buildings are considered in [1-3].

A turning point in the development of a constructive solution of multi-storey buildings can be considered a transition from load-bearing walls to a frame structure, that is, the implementation of one of the principles of steel design - the concentration of the loadbearing capacity of the structure. The functional separation of structural elements into loadbearing and walling appeared. The impetus for this was the appearance of new materials (reinforced concrete, cast iron and then steel). In the 1890s, concrete starts gaining place as a building material for load-bearing structures. European designers were among the first ones who disclosed the potential of reinforced concrete and used it in the construction as a load-bearing frame for high-rise construction [4].

The construction of the first skyscrapers with a metal frame was preceded by the appearance of such unique metal structures as Eiffel Tower and the Statue of Liberty

\footnotetext{
* Corresponding author: igasu alex@mail.ru
} 
After the devastating fire of 1871, Chicago began to build the first "skyscrapers". In 1885 , the first "multi-storey" 9-storey office building appeared here. The increase in the number of storeys was due to the deficit of free areas for construction in the business center of the city and, consequently, high prices for land. The very desire to place new buildings in the center was associated with prestige and self-promotion from the very beginning.

In the middle of the XIX century, E.Otis invented an "elevator" - a mechanical means of vertical movement of cargo with a steam power unit. This allowed a dramatic increase in the number of floors, including residential buildings. Since the invention of the liftblocking mechanism in the elevator shaft for security in case of damage (cables cut off etc.), it has become prestigious to have high-floor housing.

For the first time the metal frame was applied in England in the designs of factory buildings, but its main bearing elements were made of cast iron. The steel frame in the designs of multi-storey buildings was, apparently, first applied in Chicago in the years 1883-1885. ("Home Insurence Building", Baron Jenny), which marked the beginning of the intensive development of steel frame construction. Unfortunately, the deficit of steel products in Russia for many years has stalled the use of steel in mass construction (for example, the story of the famous Shukhov tower).

By 1902, one of the most famous high-rise buildings of Manhattan, the first Manhattan high-rise building "Flatiron Building", named so because of its unusual triangular shape, which was the result of a competent solution of the architect who had to place it at the intersection of Fifth Avenue and Broadway, crossing Manhattan diagonally. Flatiron became one of the first buildings with a steel frame, which allowed to build it with a height of 87 meters. The facade is divided into three parts: the base, lined with hewn stone, the middle main part with many levels and the upper part consisting of a penthouse with very high arches, columns and a carved eaves hanging over it. Having a three-part division with a sharp front corner, having curvature width of only two meters, Flatiron acquired the features of the antique style, reminiscent of the Renaissance palaces. Thus for the subsequent 1900-1920 years in the history of high-rise buildings-skyscrapers came the period of rampant eclecticism.

In 1913, a 59-story building, $241 \mathrm{~m}$ high, Woolworth Building (architect-eclecticist Cass Gilbert) was built in New York. It is called the modern cathedral and the "Temple of commerce". For the building, the architect chose the Neo-Gothic style, believing that it is best suited for a tower rushing upward. "Woolworth" became a model for many skyscrapers built later. This building kept the world record of height from 1913 to 1930, remaining the highest in the world. The facade was decorated with elements typical of the Gothic style, such as lancet arches, turrets and so on. It was with the erection of this building that a new word "skyscraper" entered the everyday life.

Since 1930, the tallest building in the world - 319 meters including the high spire above the conical roof of the building - was the skyscraper "Chrysler Building".

Soon this record was also broken. It was the building of the Empire State Building 1931, 102 floors, 381 meter height.

Further on and up to now the construction of high-rise buildings has turned into an unrestrained races in the vertical, a kind of sports competition - who is higher, who is faster.

A hundred-meter height line was overcome in 1890. The way this race developed further [5], may be clear from Table 1, where only the multi-storey buildings are represented, which for some time have remained altitude recorders.

A kind of a long-liver among these record holders was the Empire State building, which ranked as the highest for 41 years. As for today's record holder, it is assumed that he will not remain a long-term ringleader.

At present, the number of skyscrapers has exceeded one hundred thousand. Asia is in the lead in this marathon. If initially the engine of progress in the construction of multistorey buildings were economic considerations, then gradually the priorities shifted, and 
ambitions came to the fore. Governments and ruling elites are usually the promoters of unique skyscrapers construction (skyscrapers of Donald Trump). Although there is an opinion that these buildings are unprofitable objects.

Table 1. The progress in height.

\begin{tabular}{|l|c|c|c|}
\hline Building name & Year & Number of Storeys & Hight, m \\
\hline World Building & 1890 & 20 & 106,4 \\
\hline Manhattan Insurance & 1894 & 18 & 106,1 \\
\hline Park Row Building & 1899 & 30 & 119,2 \\
\hline Singer Building & 1908 & 47 & 186,6 \\
\hline Metropolitan Life Tower & 1909 & 50 & 213,4 \\
\hline Woolworth Building & 1913 & 57 & 241,4 \\
\hline 40 Wall Street & 1930 & 71 & 282,5 \\
\hline Chrysler Building & 1930 & 77 & 318,9 \\
\hline Empire State Building & 1931 & 102 & 443,2 \\
\hline World Trade Center & 1972 & 110 & 526,8 \\
\hline Willis Tower & 1974 & 108 & 527,3 \\
\hline Petronas Towers & 1998 & 88 & 451,9 \\
\hline Taipei 101 & 2004 & 101 & 508,0 \\
\hline Burj Dubai & 2012 & 160 & 818,0 \\
\hline
\end{tabular}

It would be desirable to note here only, that along with rectilinear forms in some buildings arch designs were applied. However, they were not involved in the work of the basic load-bearing structures of the frameworks, but were used as supporting elements rather in auxiliary structures and as decorative elements for giving the exterior appearance of the building an architectural expressiveness and originality. The latter led to a mixture of styles and was recognized as "eclecticism".

Spatial structures in the form of domes and arches have found application mainly as roofings. For example, the 27-meter atrium is the famous palm garden of the World Financial Center (architect Caesar Pelli, 1985).

\section{Types of frames of modern multi-storey buildings}

Frameworks of multi-storey buildings can be classified [4] according to their design schemes:
a) frameless with parallel bearing walls;
b) core with bearing walls;
c) box-type;
d) with cantilevered flooring slabs on the level of each floor;
e) frame with non-beam slabs;
f) with height of floor consoles at the level of each second floor;
g) with suspended floors;
h) with height-to-height trusses in staggered order;
i) frame without core;
j) frame with core;
k) frame with latticed rigidity diaphragms;
1) framework with latticed triggers and latticed core;
m) double-core structure (pipe in the pipe);
n) multi-sectional box. 

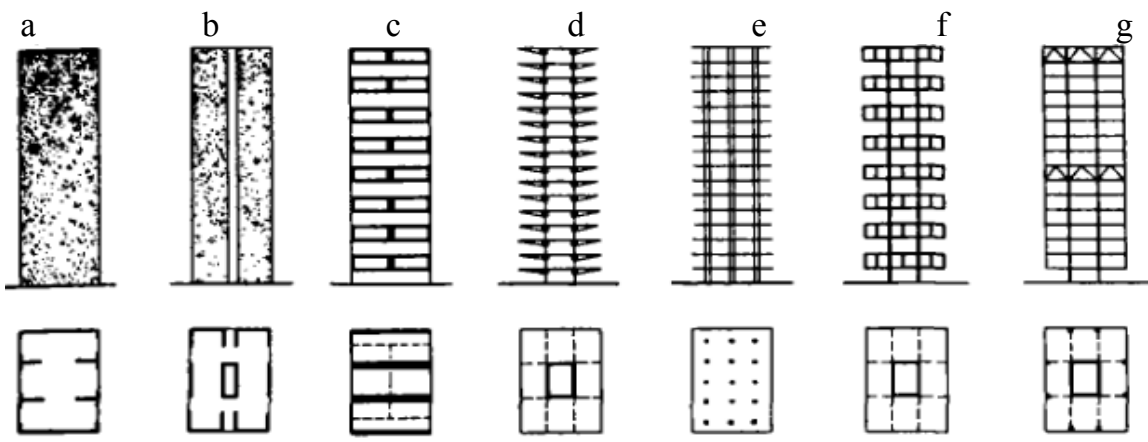

$\mathrm{h}$

$$
\text { i }
$$

j

$\mathrm{k}$
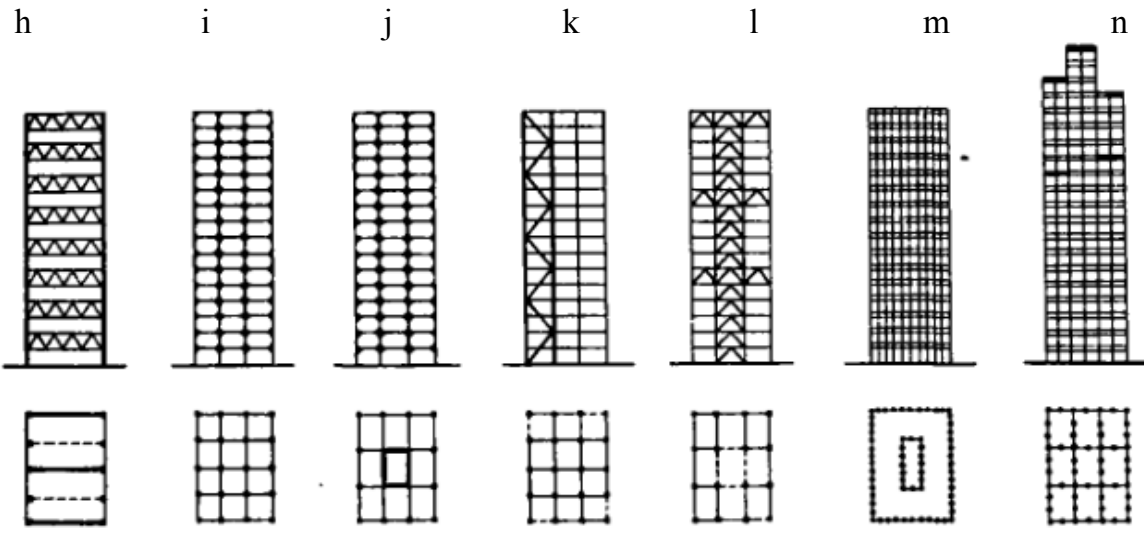

Fig. 1. Constructive schemes of high-rise buildings.

In the steel frameworks of the tallest buildings of recent decades, the last two schemes ( $m$ and $n$ ) dominate. Double-core structure (pipe in a pipe) - the outer columns and beams are located close enough to each other, and the frame of the outer walls turns into a shell with openings. The building in the whole works as a hollow tubular structure, cantilevered in the ground. The central core (pipe) increases the rigidity of the building, perceiving the horizontal loads together with the outer box (pipe). In multisectional scheme the individual boxlike sections form he complete frame according to the box scheme (bundle of pipes). External walls and intersection walls together perceive horizontal loads. In this case, an increase in the rigidity of the system is obvious. This kind of solution allows the construction of buildings of the extreme height and with a large open space of interstitial floors.

The concentration of engineering systems and, in particular, communications inside the central core, with the obvious advantages of compact placement, reduces the level of safety (viability) of the facility as a whole, and also imposes very strict restrictions on the use of the internal volume of the building. More reliable is the organization of several peripheral autonomous communication nodes, for example, if possible, along the perimeter of the circuit. It should be noted that there are high-rise buildings with two trunks (Emirates).

\section{The free space concept}

Large spans in frame structures can be overlapped by truss structures, which support the overlying or suspended lower structures. 
Despite the variety of external forms of high-rise buildings in their load-bearing steel frameworks, however, straight lines and perpendiculars predominate, and the "old good" curve stays in the background. It is no use here to refer to, mainly, decorative arches and dome coverings.

As an alternative, it is possible to consider the use of intercepting steel elements in the form of convex (arched) or concave (rigid threads, cables) of individual flat curves or segments forming shells. Such elements should work, respectively, mainly on compression or stretching or form more effective two-chord systems. The most common case, apparently, may be the circular arch. However, constructive systems of parabolic form may prove be more effective. These same elements can effectively work in regular lattices of the "column-crossbars" without openings, redistributing force flows.

Thus, the inclusion of curvilinear elements into the steel framework allows the formation of combined structural systems of a qualitatively different action type. Of course, one should be ready to challenge the additional problems with conjunctions, mounting features, layout of the internal space, interaction with the base, wind and seismic actions, and many others. Однако, возможности создания новых конструктивных форм и компоновочных решений оправдывают дополнительные трудозатраты. However, the possibilities of creating new constructive forms and space planning solutions should justify additional expenses.
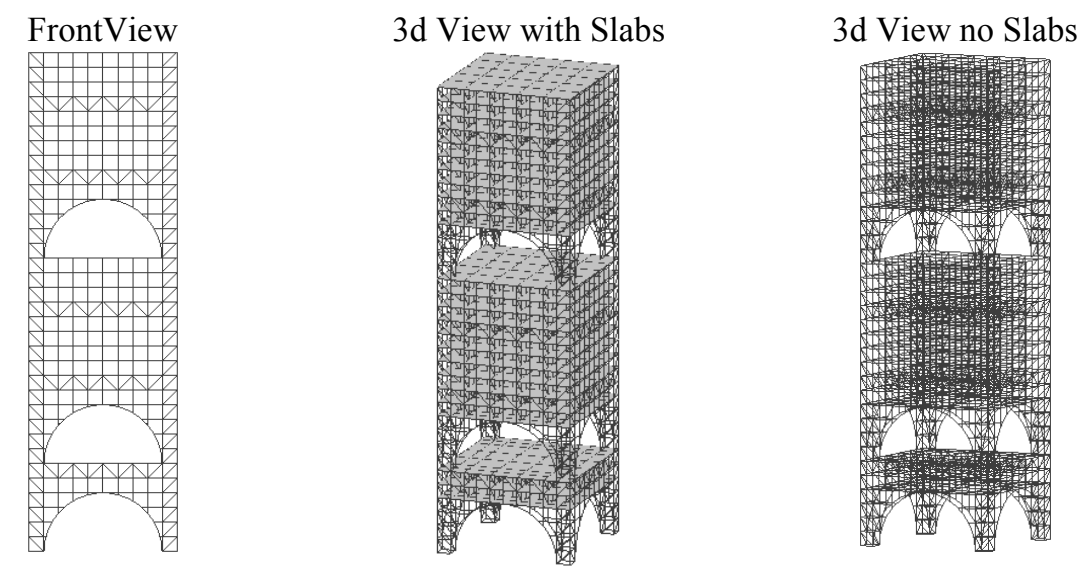

Fig. 2. Multi-storey building frame with arched supporting structures.

The wall structures are not shown here. The horizontal dimensions of the frame are $60 \times 60 \mathrm{~m}$, the height is $204 \mathrm{~m}$ ( 34 floors are $6 \mathrm{~m}$ or 68 by $3 \mathrm{~m}$ ), and the radius of the semiarch is $24 \mathrm{~m}$. Communication channels are supposed to be located in the corners inside the pylons $(6 \times 6 \mathrm{~m})$. The circuit is executed in axial lines.

Below are the sizes of sports grounds to be possibly located in these overall dimensions:

- Tennis: $23.78 \times 8.23 \mathrm{~m}$ (10.9 m - for paired tennis), height to the ceiling not less than $9.14 \mathrm{~m}$.

- Basketball: 28,0 x15,0 m, height to the ceiling not less than 7,0 m.

- Volleyball: the area is $18,0 \times 9,0 \mathrm{~m}$; a playground with adjoining zones for game 34,0x19.0 m.

- $\quad$ Mini football (according to FIFA requirements): length - $\min 20,0$ / $\max 42,0 \mathrm{~m}$; width - $\min 15,0 / \max 25,0 \mathrm{~m}$.

- Swimming pool: 50,0 x 25, 5 and 25,0 x 25,0 m - "short water".

- Curling: Length 44,5 - 45,7 m, width 4,42 -5,0 m.

- Rhythmic gymnastics, boxing, wrestling, table tennis, etc. require smaller areas. 
As show the data presented, in the space of such dimension, there is a room for office space and spectators.

In this dimension, it is possible to place retail space, entertaining (restaurants, cafes), entertainment (theater, cinema, circus, planetarium, exhibition pavilions, art galleries, etc.), gardens, greenhouses, etc. All those may have the different building marks.

A special thing is parking: for cars in the lower floors of the building, for light helicopters in the upper ones.

A free three-dimensional layout of the open space is possible. Sliding gates, stainedglass windows or solid glass may close the arched openings. The creation of such interiors and their appropriate design should facilitate the solution of psychological problems of communicative nature associated with the lack of communication, conditions for relaxation, as well as cultural and everyday life. Oval lines of interiors with high ceilings, preferably with a soft natural (or imitation) insolation, in contrast to the non-characteristic in nature aggressive angular contours, it has a beneficial effect on the psychological state and facilitates communicability.

It is possible to use such constructive solutions with the preservation of the inner bearing core.

\section{Conclusions}

With respect to the proposed concept, we can assume the following:

1. It is not impossible to use such constructive solutions in principle

2. There are perspectives of application - functionality, an unlimited range of options for layout solutions

3. This architectural concept can be regarded as a new one

4. It opens the prospect of forming a whole class of original architectural solutions

\section{References}

1. K. Kayvani, Mechanics of Structures and Materials (ACMSM23), 1 (2014)

2. K. Kayvani, Structural Engineering Solutions for Tall Buildings in Australia (2008)

3. Le Sun, International Journal of High-Rise Buildings, 5, 2 (2016)

4. W. Schueller, High-Rise Building Structures (1977)

5. A. Perelmuter, Essays on the history of metal structures (2015) 